\title{
THE USE OF REACTION GALORIMETRIG METHODS FOR MEASURING HEATS OF FORMATION OF ORGANO-METALLIC GOMPOUNDS
}

\author{
H. A. Skinner, J. E. Bennett and J. B. Pedley \\ University of Manchester, U.K.
}

The measurement of the heats of formation of organo-metallic compounds presents, usually, a difficult task to the experimental thermochemist. Thus the method of combustion in a conventional bomb-calorimeter, although it has been applied to a number of metallic alkyls in recent years ${ }^{1}$ and yielded valuable results, is nevertheless not entirely satisfactory. The difficulty is that complete oxidation of the organo-metallic compound is not always attained, and the metal may be left, after the combustion, in a partially oxidized state, as a mixture of free metal, oxides, and possibly carbonate and carbide. The development of the rotating-bomb technique offers a solution of this major difficulty, and successful studies have already been reported by Scott, Good and Waddington ${ }^{2}$ on the combustion of lead tetraethyl, and by Good, Fairbrother and Waddington ${ }^{3}$ on manganese carbonyl. One can therefore feel confident that in due course precision measurements of combustion heats of organo-metallic compounds will be made.

However, it is desirable that methods other than that of combustion should be investigated, not only to provide independent checks on combustion results, but also to develop reaction calorimetric methods. Several typical reactions of organo-metallic compounds are potentially suitable for heat of formation measurements, but comparatively few such thermal studies have as yet been made. Some of these studies are briefly discussed below.

\section{HYDROLYSIS REACTIONS}

Several of the alkyls of the metals belonging to Groups I, II, and III are easily hydrolysed by water, or by dilute acids, at room temperature. Measurements of heats of hydrolysis are available for cadmium dimethyl, cadmium diethyl, zinc dimethyl, and zinc diethyl, from which heats of formation have been derived ${ }^{4}$. It should be possible to extend studies of this type to the alkyls of the alkali metals and the alkaline earths, to beryllium alkyls, and the alkyls of aluminium and gallium. Apart from manipulative and preparative difficulties, the main problem is that of controlling the vigour of the hydrolysis reactions. In this connection, the studies already made on the hydrolysis of zinc and cadmium alkyls could be improved upon by hydrolysis in a diluent solvent. 


\section{HALOGENATION REAGTIONS}

Many metallic alkyls readily react with halogens, and in suitable cases these reactions can be studied thermochemically, and so provide useful heat of formation data. Examples already investigated include the iodination of cadmium dimethyl and diethyl, the iodination of zinc diethyl4, and the iodination of gallium trimethyl ${ }^{5}$. Thermochemical studies on the iodination and bromination of a number of mercury dialkyls ${ }^{6}$ have been made via the pairs of reactions $(\mathrm{X}=\mathrm{Br}$, or $\mathrm{I})$ :

$$
\begin{aligned}
& \mathrm{HgR}_{2}+\mathrm{X}_{2} \rightarrow \mathrm{HgRX}+\mathrm{RX} \\
& \mathrm{HgR}_{2}+\mathrm{HgX}_{2} \rightarrow 2 \mathrm{HgRX}
\end{aligned}
$$

from which the heat of total halogenation:

$$
\mathrm{HgR}_{2}+2 \mathrm{X}_{2} \rightarrow \mathrm{HgX}_{2}+2 \mathrm{RX}
$$

was derived.

Table 1 summarizes the heat of formation data on metal alkyls obtained by these reaction calorimetric studies: in the same table, the heats of formation derived from combustion heats are also given, where available, for purposes of comparison?. The agreement between the heats of formation derived from combustion and reaction calorimetric methods is very fair,

\begin{tabular}{|c|c|c|c|}
\hline \multirow{2}{*}{ Compound } & \multirow{2}{*}{ Method } & \multicolumn{2}{|c|}{$\Delta H_{\mathrm{f}}^{\mathrm{O}}(\mathrm{kcal} / \mathrm{mole})$} \\
\hline & & Reaction calor. & Combustion \\
\hline $\begin{array}{l}\mathrm{CdMe}_{2(1 .)} \\
\mathrm{CdEt}_{2(1 .)} \\
\mathrm{ZnMe}_{2(1 .)} \\
\mathrm{ZnEt}_{2(1 .)} \\
\mathrm{HgMe}_{2(1 .)} \\
\mathrm{HgEt}_{2(1 \cdot)} \\
\mathrm{HgPr}_{2(1 .)} \\
\mathrm{Hg}^{1} \mathrm{Pr}_{2(1 .)} \\
\mathrm{HgPh}_{2(c .)} \\
\mathrm{GaMe}_{3(1 .)}\end{array}$ & $\begin{array}{c}\text { Hydrolysis } \\
\text { Bromination } \\
\text {," } \\
\text { ", } \\
\text { Reaction with HCl } \\
\text { Iodination }\end{array}$ & $\begin{array}{l}+16.7 \pm 0.5 \\
+14.5 \pm 0.5 \\
+6.3 \pm 1 \\
+4.3 \pm 1 \\
+12.3 \pm 2 \\
+5.2 \pm 2 \\
-8.6 \pm 3 \\
-3.8 \pm 3 \\
+65.4 \pm 2 \\
-14.5 \pm 8\end{array}$ & $\begin{array}{l}+19.6 \pm 3 \\
+6.5 \pm 2 \\
+4.1 \pm 3 \\
+14.3 \pm ? \\
+6.5 \pm ? \\
-\overline{-} \\
+66.9 \pm 2 \\
-17.6 \pm 3\end{array}$ \\
\hline
\end{tabular}
although neither method has yet given results of high precision.

Table 1. Heats of formation of organo-metallic compounds

\section{HEATS OF HYDROBORATION}

Brown and Subba $\mathrm{RaO}^{8}$ have recently reported that in the presence of organic ethers, diborane adds to olefins with remarkable ease and speed at room temperature to form organoboranes in high yields:

$$
6 \mathrm{RGH}=\mathrm{CH}_{2}+\mathrm{B}_{2} \mathrm{H}_{6} \rightarrow 2\left(\mathrm{RCH}_{2} \mathrm{CH}_{2}\right)_{3} \mathrm{~B}
$$

Since the heats of formation of olefins and diborane are already known, the measurement of heats of hydroboration provide a route to the heats of formation of organoboranes.

J. E. Bennett and J. B. Pedley have recently made a preliminary series of measurements on the heats of addition of diborane to the olefins hex-1-ene, 
oct-1-ene, and oct-2-ene, in diglyme $\left(\mathrm{CH}_{3}\left(\mathrm{OCH}_{2} \mathrm{CH}_{2}\right)_{2} \mathrm{OCH}_{3}\right)$ solution. They used a silver-plated copper calorimeter containing a Pyrex glass reaction vessel immersed in water: the calorimeter was placed inside a metal jacket within a thermostat. The temperature of the calorimeter was measured by a shielded thermistor element (Stantel, F/2311/300) immersed in the calorimetric fluid.

The reaction vessel was similar in design to that used by Brown and Gintus $^{9}$ in their measurements of the heat of solution of diborane in various solvents. The diborane gas entered the reaction chamber (Figure 1) through the glass sinter, $\mathrm{K}$, which was sealed with sufficient mercury $\left(\sim 1 \mathrm{~cm}^{3}\right)$ to allow the sinter to operate as a valve. The reaction chamber contained a known amount of diglyme-olefine solution (usually $\sim 28 \mathrm{~cm}^{3}$ ) stirred at constant speed ( $136 \mathrm{rev} / \mathrm{min})$ by a stainless steel stirrer through a ball and socket joint, A. The exit gases escaped through the filling tube, $\mathrm{D}$, and passed into a water-containing trap outside the calorimeter, the purpose of which was to decompose any diborane gas escaping from the reaction vessel.

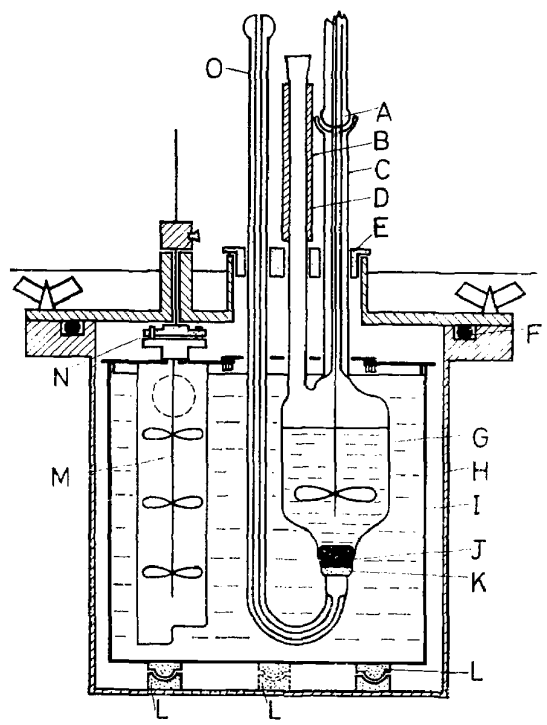

Figure 1. Calorimeter and reaction vessel: A, C, ball and socket joint: Pyrex capillary; B, small electric heater; D, exit tube; E, polythene spacers; F, O-ring seal; G, Pyrex reaction vessel; $\mathrm{H}$, outer calorimeter jacket; I, silver-plated copper can; J, mercury; $\mathrm{K}$, glass sinter ; L, Bakelite pegs; M, stirrer; N, stirrer connection

The calorimeter can contained a propeller stirrer, $\mathbf{M}$, located in a brass tube, an electric heater for calibration, and a shielded thermistor element: it was charged with $700 \mathrm{~g}$ of distilled water for each experiment, and sealed with a lid, slotted to take the inlet tubes of the reaction vessel and support it firmly in position. The can was supported by three bakelite pegs, L, inside a brass jacket, closed at the top by a flanged lid: the whole assembly was immersed in a water thermostat bath. 
The experimental procedure was as follows.

The reaction vessel was cleaned and thoroughly dried, and swept out with dry nitrogen: it was then charged with a solution containing a known amount of pure diglyme and olefin, and placed in position in the calorimeter can. The calorimeter was located in the jacket, the flange-lid bolted on, and the assembly immersed in the thermostat. The calorimeter and reaction vessel stirrers were set in motion, and the calorimeter heater used to bring the calorimeter temperature within $\frac{1}{2}^{\circ} \mathrm{C}$ of $25^{\circ} \mathrm{C}$.

Before introducing the diborane in quantity, a small amount (usually 5-10 $\mathrm{cm}^{3}$ ) was passed through the filling lines (Pyrex capillary), via the mercury-sealed sinter into the diglyme solution: this "flushing" with diborane was intended to rid the filling lines of traces of moisture, and to destroy traces of moisture and other reactive impurities remaining in the diglyme solvent. The diborane flushing was immediately followed by a flushing with pure dry nitrogen. The system was then allowed time to regain a steady thermal state.

Thermistor resistance readings were recorded at regular intervals to establish the fore-rating period, following which the reaction proper was carried out, by introducing a measured volume (usually $\sim 50 \mathrm{~cm}^{3}$ ) of diborane into the reaction vessel from a calibrated gas-burette. The reaction time was usually about $20 \mathrm{~min}$. After introducing the diborane, the reaction vessel was again flushed out with dry nitrogen, and the afterrating thermistor readings recorded.

\section{Preparation of compounds}

Diborane was prepared by treating sodium boron hydride with boron trifluoride-etherate, in diglyme solvent, as described by Brown and Rao ${ }^{8}$. The diborane gas was purified by low-temperature fractional distillation in an all-glass grease-free vacuum system. The diborane was freshly prepared before each experiment in quantities of $\sim 100 \mathrm{~cm}^{3}$, sufficient for one experiment only.

Diglyme was supplied by the Ansul Chemical Company, and purified by distillation under reduced pressure $(20 \mathrm{~mm} \mathrm{Hg})$ from lithium aluminium hydride. The purified stock solution was stored under dry nitrogen.

Hex-1-ene was a high-purity ( 99.9 per cent) sample, supplied by the Chemical Research Laboratory, D.S.I.R., Teddington.

Oct-1-ene and oct-2-ene were commercial samples (Light and Co.), purified by distillation from sodium and by fractional distillation.

Cyclohexene was similarly purified.

In the latter cases, the degree of purity of the hydrocarbons was not known, nor were purity measurements made.

\section{Calibration}

The calorimeter was calibrated electrically by the substitution method. The heat exchange between calorimeter and jacket during an experiment was evaluated from the time-temperature curves by the RegnaultPfaundler method. From the spread in the measured calibration constants, the calorimeter performance was reproducible within limits of $\pm \frac{1}{4}$ per cent. 


\section{Units}

Heat quantities are expressed in thermochemical calories, defined by $1 \mathrm{cal} \equiv 4 \cdot 1840$ abs. joules. The measurements were made at $25^{\circ} \mathrm{G}$.

In estimating the amount of diborane from the volume used, it was accepted that 1 mole of $\mathrm{B}_{2} \mathrm{H}_{6}$ at N.T.P. occupies $22 \cdot 15 \mathrm{l}$.

\section{Results}

In order to test the calorimetric method, a number of measurements were made of the heat of hydrolysis of diborane gas. In these experiments, the reaction vessel was charged with $25 \mathrm{~cm}^{3}$ of pure water, and a measured volume of diborane was introduced into the vessel. Of the total diborane used, only 70-80 per cent was hydrolysed in the reaction vessel, the remainder being carried away by the effluent hydrogen gas and hydrolysed outside the calorimeter in the water-filled trap. The amount of diborane hydrolysed in the reaction vessel was determined from the amount of boric acid recovered from it after the experiment; similarly, the amount of boric acid formed in the water-trap measured the diborane escaping hydrolysis in the reaction vessel.

From a series of independent purity determinations, it was established that the average purity of the diborane used in these experiments was 98.9 per cent.

To calculate the heat of hydrolysis, it was necessary to define the amount of diborane hydrolysed in the reaction vessel in each experiment. This was done in two ways:

(1) from the amount of boric acid recovered from the reaction vessel;

(2) from the amount of diborane introduced into the reaction vessel, less that escaping from it, as determined by the amount of boric acid recovered from the water trap.

The two methods of estimating the amount of reaction generally agreed with one another within limits of 1 per cent, the mean of the two measures being accepted as correct.

It was assumed that the hydrogen gas formed in the reaction vessel was saturated with water vapour before escaping the calorimeter, and that an evaporation heat correction was necessary to allow for this effect. This amounted to $2 \cdot 0 \mathrm{kcal} / \mathrm{mole}$ of diborane hydrolysed in the reaction vessel. The heat of hydrolysis results are summarized in Table 2.

Table 2. Heat of hydrolysis of diborane gas

\begin{tabular}{|c|c|c|c|c|}
\hline Expt. & $\begin{array}{l}\mathrm{B}_{2} \mathrm{H}_{6} \text { used } \\
\text { (m. moles) }\end{array}$ & $\begin{array}{c}\mathrm{B}_{2} \mathrm{H}_{6} \text { hydrolysed } \\
\text { in R.V. (m. moles) }\end{array}$ & $\begin{array}{l}\text { Heat evolved } \\
\quad \text { (cal) }\end{array}$ & $\underset{\left(\mathrm{kcal} / \text { mole of } \mathrm{B}_{2} \mathrm{H}_{6}\right)}{-\Delta H_{\text {hydrot. }}}$ \\
\hline $\begin{array}{l}1 \\
2 \\
3 \\
4\end{array}$ & $\begin{array}{l}2 \cdot 070 \\
2 \cdot 034 \\
1 \cdot 897 \\
2 \cdot 249\end{array}$ & $\begin{array}{l}1 \cdot 511 \\
1.777 \\
1 \cdot 307 \\
1 \cdot 813\end{array}$ & $\begin{array}{l}166 \cdot 0 \\
194 \cdot 5 \\
142 \cdot 5 \\
199 \cdot 4\end{array}$ & $\begin{array}{c}111.8 \\
111.5 \\
110.9 \\
112.0 \\
\text { value }=111.5 \pm 0.4\end{array}$ \\
\hline
\end{tabular}

The overall uncertainty in the mean $\Delta H_{\text {hydrol. is appreciably greater }}$ than the spread of the observed results, if allowance is made for the accuracy 
of the calorimeter $\left( \pm \frac{1}{4}\right.$ per cent), and the uncertainty in analysis ( $c a . \pm \frac{1}{2}$ per cent) of the amount of $\mathrm{B}_{2} \mathrm{H}_{6}$ hydrolysed in each run; nevertheless, the agreement with the value obtained by Prosen, Johnson and Pergiel ${ }^{10}$, $\Delta H_{\text {hydrol. }}=-11 \mathrm{l} .46 \pm 0.54 \mathrm{kcal} / \mathrm{mole}$, is most satisfactory.

\section{Hex-1-ene}

The reaction occurring with hex-I-ene in solution was presumed to be:

$$
\mathrm{B}_{2} \mathrm{H}_{6} \text { (gas) }+6 \mathrm{C}_{6} \mathrm{H}_{12} \text { (diglyme, soln.) } \rightarrow 2 \mathrm{~B}\left(\mathrm{C}_{6} \mathrm{H}_{13}\right)_{3} \text { (diglyme, soln.) }
$$

and the observed heat of reaction, $\Delta H_{\text {obs., }}$ refers to this reaction. It is important to stress that we have not established by analysis of the products that reaction (i) occurs without any contaminating side-reactions. We have considered the possibility of incomplete reaction, with the formation of $\left(\mathrm{C}_{6} \mathrm{H}_{13}\right)_{2} \mathrm{BH}_{2} \mathrm{~B}\left(\mathrm{C}_{6} \mathrm{H}_{13}\right)_{2}$; however, addition of water to the reaction products did not result in a significant evolution of gaseous products, so that this possibility would seem to be eliminated. We have in all experiments used a large excess of hex-1-ene relative to diborane. The amount of diborane consumed by reaction (i) in each run was determined from the amount of diborane introduced into the reaction vessel, less that escaping and subsequently hydrolysed in the water-trap outside the calorimeter. Reaction (i) is extremely rapid, and only very small amounts of diborane gas were found to escape the reaction zone.

Measurements were made separately in a small Dewar vessel calorimeter of the heats of solution in diglyme of hex-l-ene, and of pure boron trihexyl. Solution heat corrections were made to $\Delta H_{\mathrm{obs}}$. in order to obtain $\Delta H_{2}$ of the simple reaction:

$$
\mathrm{B}_{2} \mathrm{H}_{6}(\mathrm{~g} .)+6 \mathrm{C}_{6} \mathrm{H}_{12(1 .)} \rightarrow 2 \mathrm{~B}\left(\mathrm{C}_{6} \mathrm{H}_{13}\right)_{3}(1 .)
$$

In each experiment, a preliminary "flushing" of the reaction vessel and contents with diborane was carried out to remove traces of moisture. In some experiments, the diglyme solvent was pre-treated with diborane in the calorimeter before addition of hex-1-ene.

The results obtained are preliminary in nature, since we intend to repeat the investigation using a larger reaction vessel and a more precise calorimeter, and also to improve the present analytical technique. The details of a representative sample of the more satisfactory runs are given in Table 3.

\begin{tabular}{|c|c|c|c|c|}
\hline & Run No. & 1 & 2 & 3 \\
\hline $\begin{array}{l}\text { (i) flush } \\
\text { (ii) water-trap } \\
\text { (iii) consumed }\end{array}$ & & $\begin{array}{l}0.457 \\
0.015 \\
2 \cdot 051\end{array}$ & $\begin{array}{l}0.405 \\
0.005 \\
1.887\end{array}$ & $\begin{array}{l}0.477 \\
0.008 \\
2 \cdot 062\end{array}$ \\
\hline $\begin{array}{ll}\mathrm{C}_{6} \mathrm{H}_{12} & \text { (i) added } \\
\text { (m. moles) } & \text { (ii) consumed }\end{array}$ & & $\begin{array}{l}15 \cdot 7 \\
12 \cdot 3\end{array}$ & $\begin{array}{l}14 \cdot 4 \\
11 \cdot 3\end{array}$ & $\begin{array}{l}21 \cdot 1 \\
12 \cdot 3\end{array}$ \\
\hline $\begin{array}{l}\Delta H_{\text {obs. }}\left(\mathrm{kcal} / \mathrm{mole} \text { of } \mathrm{B}_{2} \mathrm{H}_{6}\right) \\
\Delta H_{\text {soln. }}\left(\mathrm{kcal} / 6 \text { moles of } \mathrm{C}_{6} \mathrm{H}_{12}\right) \\
\Delta H_{\text {soln. }}\left(\mathrm{kcal} / 2 \text { moles of } \mathrm{B}\left(\mathrm{C}_{6} \mathrm{H}_{13}\right)_{3}\right) \\
\Delta H_{2} \quad\left(\mathrm{kcal} / \mathrm{mole} \text { of } \mathrm{B}_{2} \mathrm{H}_{6}\right)\end{array}$ & & $\begin{array}{r}-137 \cdot 4 \\
4 \cdot 5 \\
0 \cdot 5 \\
-133 \cdot 4\end{array}$ & $\begin{array}{r}-135 \cdot 9 \\
4 \cdot 5 \\
0 \cdot 5 \\
-131 \cdot 9\end{array}$ & $\begin{array}{r}-137 \cdot 7 \\
4 \cdot 1 \\
0 \cdot 5 \\
-134 \cdot 1\end{array}$ \\
\hline
\end{tabular}

Table 3. Heat of hydroboration of Hex-1-ene 


\section{THE USE OF REACTION CALORIMETRIC METHODS}

The mean value, $\Delta H_{2}=-133.1 \mathrm{kcal} / \mathrm{mole}$, is subject to experimental error limits of $c a . \pm 2 \mathrm{kcal} / \mathrm{mole}$, but the overall error limits may be larger than this in view of the assumptions made regarding the reaction which occurs. From the mean $\Delta H_{2}$ value, we may derive $\Delta H_{\mathrm{f}}^{\mathrm{o}}\left(\mathrm{B}\left(\mathrm{C}_{6} \mathrm{H}_{13}\right)_{3}(1).\right)=$ $-114.7 \mathrm{kcal} / \mathrm{mole}$, assuming the values $\Delta H_{\mathrm{f}}^{\mathrm{o}}\left(\mathrm{B}_{2} \mathrm{H}_{6}(\mathrm{~g}).\right)=7.5 \mathrm{kcal} / \mathrm{mole}$ (Wagman, Munson, Evans, and Prosen ${ }^{11}$, and $\Delta H_{\mathrm{f}}^{\mathrm{o}}\left(\mathrm{C}_{6} \mathrm{H}_{12(1 .)}\right)=-17 \cdot 28$ $\mathrm{kcal} / \mathrm{mole}$ (Camin and Rossini ${ }^{12}$ ).

\section{Oct-1-ene, Oct-2-ene, Cyclohexene}

The experiments on the octenes and cyclohexene have been less thorough than those on hex-1-ene, and we shall not present detailed results. In the case of oct-1-ene, the mean value of $\Delta H_{\text {obs. }}=-136.6 \mathrm{kcal} / \mathrm{mole}$ was almost the same as that obtained with hex-l-ene, and, corrected for the solution heats, gave $\Delta H_{2}=-132.6 \mathrm{kcal} / \mathrm{mole}$. The heat of reaction for oct-2-ene (a mixture of cis- and trans-isomers) was markedly less than that for oct-1-ene: we obtained $\Delta H_{\text {obs. }} \simeq-123 \mathrm{kcal} / \mathrm{mole}$, and $\Delta H_{2} \simeq-118.5$ $\mathrm{kcal} / \mathrm{mole}$. In the case of cyclohexene some precipitation of tricyclohexyl boron from diglyme solution occurred during the runs, and there was also some evidence of incomplete hydroboration. It seemed clear, however, that the heat of reaction with cyclohexene is much less (by $\sim 20 \mathrm{kcal} / \mathrm{mole}$ ) than with hex-1-ene.

\section{DISGUSSION}

From heat of combustion studies, Prosen and Johnson ${ }^{13}$ have derived $\Delta H_{\mathrm{f}}^{\mathrm{o}}=-83.9 \mathrm{kcal} / \mathrm{mole}$ for boron tributyl (liq.), and Haseley, Garrett and Sisler ${ }^{14}$ reported $\Delta H_{\mathrm{f}}^{0}=-75 \pm 6 \mathrm{kcal} / \mathrm{mole}$ for boron tri-sec-butyl. From these data, in conjunction with the available values ${ }^{11,}{ }^{15} \Delta H_{\mathrm{f}}^{\mathrm{o}}\left(\mathrm{B}_{2} \mathrm{H}_{6 \cdot(\mathrm{g} .)}\right)$ $=7.5 \mathrm{kcal} / \mathrm{mole}, \Delta H_{\mathrm{f}}^{\mathrm{o}}\left(\right.$ but-1-ene $\left._{(\mathrm{l} .)}\right)=-5.09 \mathrm{kcal} / \mathrm{mole}, \Delta H_{\mathrm{f}}^{\mathrm{o}}$ (cis-but2-ene $\left(\right.$ (1.) $\left._{1}\right)=-7.12 \mathrm{kcal} / \mathrm{mole}$, and $\Delta H_{\mathrm{f}}^{\mathrm{o}}\left(\right.$ trans-but-2-ene $\left._{\left(\mathrm{l}_{\mathrm{f}}\right)}\right)=-7.97 \mathrm{kcal} /$ mole, we may calculate the heats of the following reactions, which correspond to reaction (ii) :

$$
\begin{aligned}
& \mathrm{B}_{2} \mathrm{H}_{6(\mathrm{~g} .)}+6 \text { But-1-ene }(\mathrm{l.}) \rightarrow 2 \mathrm{~B}(\mathrm{n}-\mathrm{Bu})_{3(\mathrm{~L} .)} \Delta H_{\text {calc. }}=-144 \cdot 8 \\
& \mathrm{~B}_{2} \mathrm{H}_{6 \text { (g.) }}+6 \text { cis-But-2-ene }(\mathbf{l . )}) \rightarrow 2 \mathrm{~B}(\sec -\mathrm{Bu})_{3(1 .)} \Delta H_{\text {calc. }}=-114 \cdot 8 \\
& ( \pm 12) \mathrm{kcal} / \mathrm{mole}
\end{aligned}
$$

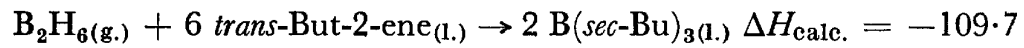

$$
\begin{aligned}
& \text { (士12) } \mathrm{kcal} / \mathrm{mole}
\end{aligned}
$$

In comparison, the value we have obtained for $\Delta H_{2}$ with hex-1-ene and oct-1-ene is $c a .10 \mathrm{kcal} / \mathrm{mole}$ smaller than that calculated for reaction with but-1-ene; on the other hand, our value for $\Delta H_{2}$ with oct-2-ene is $c a .10$ $\mathrm{kcal} / \mathrm{mole}$ larger than that calculated for reaction with but-2-ene. In the latter case, the difference is covered by the large error limits attached to the combustion heat measurements of Haseley et al. ${ }^{14}$. The discrepancy in the former case is not easily accounted for at this stage, but both our own measurements and those of Prosen and Johnson ${ }^{13}$ are preliminary in character, and may be subject to revision later. 


\section{Note added in proof}

A more complete account of the hydroboration studies will appear in 7. Chem. Soc. in 1961. The final results differ somewhat from those given here, mainly in that corrections for the heats of solution of products have been more accurately measured.

\section{References}

1 L. H. Long and R. C. W. Norrish. Phil. Trans. Roy. Soc. (London) A, 241, 587 (1949)

L. H. Long and J. F. Sackman. Trans. Faraday Soc., several papers since 1954

D. M. Fairbrother and H. A. Skinner. Trans. Faraday Soc., 52, 956 (1956)

2 D. W. Scott, W. D. Good and G. Wardington. 7. Phys. Chem., 60, 1090 (1956)

${ }^{3}$ W. D. Good, D. M. Fairbrother and G. Waddington. F. Phys. Chem., 62, 853 (1958)

4 A. S. Carson, K. Hartley and H. A. Skinner. Proc. Roy. Soc. (London) A, 195, 500 (1949)

A. S. Carson, K. Hartley and H. A. Skinner. Trans. Faraday Soc., 45, 1159 (1949)

5 P. A. Fowell and C. T. Mortimer. J. Chem. Soc., 1958, 3734

${ }^{6}$ K. Hartley, H. O. Pritchard and H. A. Skinner. Trans. Faraday Soc., 46, 1019 (1950), 47, 254 (1951) and later papers in Trans. Faraday Soc., by H. A. Skinner et al.

' See H. A. Skinner. Roy. Inst. Chem. Monographs, No. 3 (1958) for detailed references

${ }^{8}$ H. C. Brown and B. C. Subba Rao. 7. Org. Chem., 22, 1136 (1957)

${ }^{9}$ H. C. Brown and D. Gintus. J. Am. Chem. Soc., 78, 5378 (1956)

${ }^{10}$ E. J. Prosen, W. H. Johnson and F. Y. Pergiel. Nat. Bur. Standards (U.S.) Report No. 1552 (1952)

11 D. D. Wagman, T. R. Munson, W. H. Evans and E. J. Prosen. Nat. Bur. Standards (U.S.) Report No. 3456 (1954)

12 D. L. Camin and F. D. Rossini. J. Phys. Chem., 60, 1446 (1956)

13 E. J. Prosen and W. H. Johnson. Referred to in Ref. 11

14 E. A. Haseley, A. B. Garrett and H. H. Sisler. F. Phys. Chem., 60, 1136 (1956)

15 American Petroleum Institute Research Project 44: Carnegie Institute of Technology, Pittsburgh 